\title{
Descriptive study of breast problems in women who present to the general outpatient of a tertiary hospital in eastern region of Nepal
}

\author{
R Giri, R Bhandari, I Mahato, M Poudel, S Kumari, AK Yadav \\ Department of General Practice and Emergency Medicine \\ BPKIHS, Dharan, Nepal
}

\begin{abstract}
Background: Breast problems are common among female patient attending general outpatient. Although the problem is expected to have significant morbidity, patients usually hide or present late for breast related problems in Nepal. Objective: To measure the pattern of breast diseases and its frequency and distribution in different age groups among patients attending general outpatient department at BPKIHS, Nepal. Methods: A crosssectional study was conducted in general outpatient department (GOPD) of B.P.Koirala Institute of Health Sciences (BPKIHS) during a period of six months. Women of all age groups presenting with breast problem were included. Clinical assessment, fine needle aspiration cytology (FNAC) and radiology were done. Mammography being unavailable at the hospital, ultrasonography was the preferred method of imaging. Results: Hundred cases of breast diseases were assessed. The benign breast disease (BBD) was the commonest finding (96\%). Among BBD, fibroadenoma was the commonest (32\%) followed by breast abscess (26\%) and mastalgia (22\%) including cyclic and non cyclic. The common age groups of involvement were 30-39 years for fibroadenoma, 20-29 years for breast abscess, 30-39 years for cyclic mastalgia, 40- 49 years for non cyclic mastalgia and 70-79 years for breast cancer. Conclusion: BBD is the most common breast problem in women. Among $\mathrm{BBD}$, fibroadenoma was the most common.
\end{abstract}

Keywords: benign breast disease (BBD), fibroadenoma, breast abscess, breast cancer

\section{Introduction}

Breast disease in women includes a spectrum of benign and malignant disorders. BBD is common with an estimate of over one half of the female population seeking medical advice for breast problems during lifetime. ${ }^{1}$

In many western countries the majority of women first consult with their general practitioner and are managed by them initially. ${ }^{2-3}$ In these countries, a palpable mass, breast pain and nipple discharge are the most common breast problems for which women

Address for correspondence

Dr Rajani Giri

Assistant Professor

Department of General Practice and Emergency Medicine

B.P. Koirala Institute of Health Science, Dharan, Nepal

Email:dr_rajanigiri@hotmail.com seek medical advice. ${ }^{4}$ A survey of GOPD conducted in March 2006, assessing the reasons for visit employing International classification of primary care found Breast lump and breast pain to rank $30^{\text {th }}$ and represented $2 \%$ of all the reason for encounters at BPKIHS. $^{5}$

Studies conducted in Nepal and other developed country set up shows Benign Breast Disease to be the commonest ${ }^{1,6,7}$ ranging from $71 \%{ }^{8}$ to $93 \% .{ }^{6}$ In these studies among Benign Breast Disease fibroadenoma were the commonest lesion encountered. ${ }^{6,8}$ Mastalgia is also common problem, in western society. ${ }^{9}$ But the study and treatment of mastalgia is mostly ignored in nonwesternpopulation. ${ }^{10}$ This is true in Nepal as well as in India with a few notable exception. Sukla ${ }^{11}$ and 
later Khanna ${ }^{12}$ estimated it to account for $70 \%$ of BBD.

Malignant lesion of the breast is major concern and the second most commonly diagnosed cancer in Nepal. ${ }^{13-15}$ There are several established risk factors for breast cancer like advanced age, environmental factors, hormonal factors including age at menarche and menopause, parity, age at first child birth, family history of breast cancer, oral contraceptive, hormonal replacement therapy and certain condition like BBD. ${ }^{16-18}$

However, in Nepal women with cancer present in late stage due to unawareness of the disease.$^{14,15,19}$ They are more likely to present with only symptomatic breast lump and ignore the asymptomatic breast lumps. Many studies show that majority of breast presentations are benign. ${ }^{1,6-10}$ Therefore, an understanding the type of breast problems that are most likely to present to doctors in primary health provider setting is very useful. This study sets out to measure the pattern of breast problems, its frequency and distribution in different age groups among patients attending general outpatient department at BPKIHS, Nepal.

\section{Methods}

This is a cross sectional study conducted in general outpatient department of BPKIHS Dharan, Nepal. A convenient sampling method was used. The researcher was available for two weekdays in the GOPD during which the samples were collected. Hundred patients with breast problems were evaluated during a period of six months. (July December 2006). Women of all age group presenting with breast problem were included and a detail history and examination was performed in these patients. History included age at menarche and menopause, marital status, parity, age at first pregnancy breast feeding history, use of hormone replacement therapy, family history, previous breast biopsy, and radiation to identify the associated risk factors for breast cancer

Physical examination included clinical breast examination (CBE) of the lump using "twelve stroke method" by the researcher with special attention to any sign of malignancy. Examination of axilla, abdomen, chest wall and skeletal system were carried out if there was any evidence of malignancy.
In order to support clinical findings, all patients who had palpable lumps were referred for supplementary tests (radiographic imaging and FNAC). This diagnostic triad is known as the "Triple Test". 3, 9,16 As mammography was not available ultrasonography was done in women with palpable breast lump and in some cases with breast pain. In patient presenting with breast pain only and no lump in CBE, they were categorized as mastalgia (cyclic and noncyclical). Informed consent was taken from each respondent.

\section{Results}

A total of hundred cases with breast problems were assessed. BBD were frequent whereas malignant cases were rare (4). Among BBD, fibroadenoma was the commonest (32\%) followed by breast abscess (26\%), mastalgia (22\%) (cyclic,noncyclic), cyst and fibroadenosis in decreasing order of frequency respectively. Uncommon lesions were also found in this study like papiloma of nipple $(n=3)$, and galactocele $(n=2)$. Phyllodes tumor also known as cystosarcoma phylloides are a rare variant and was seen in one case.

Total seventy eight percent patients presented with a lump in the breast, the commonest being fibroadenoma constituting thirty two percent of all breast problems. Almost fifty percent of the cases of the breast lump presented due to fibroadenoma. Fibroadenoma of the breast was commonest in the thirties (56\%), followed by in twenties (25\%).

Twenty six percent of the cases with the breast problem had breast abscess needing emergent management. Majority of the breast abscess (twenty one out of twenty six) were in age group of twenty to twenty nine. None of the cases had breast abscess above the age of thirty.

A total of twenty two cases presented with breast pain as a sole problem. Out of which sixteen had cyclic and six had non cyclic mastalgia. The range of age of the patient with cyclic mastalgia was 1440 years. The range of patients in non-cyclic mastalgia was $38-50$ years. Thus patients with cyclic mastalgia were younger than those with non-cyclic mastalgia.

Only four cases out of hundred were diagnosed with malignant lesion. All the four cases were detected with advanced stage of malignancy at presentation itself and were in $8^{\text {th }}$ decade of life. None of them had established risk factors mentioned earlier. 
The duration of symptoms before presentation in patient with breast lump (not including abscess) was as early as one week to 180 month with a mean of 11.30 month with SD +/-26.09.

Among all the surveyed women who came with the breast problems other than breast abscess, only $28.37 \%(n=21)$ were familiar with breast self examination technique and carried out regularly. The rest $(n=53)$ either were unfamiliar with the technique or simply didn’t use it.

\section{Discussion}

In the present study BBD was the most common (96\%) type of breast lesion seeking medical advice for breast problem at general outpatients which was similar to other studies which also showed BBD to be the commonest ${ }^{1,6,7}$ ranging from $71 \%{ }^{8}$ to $93 \%$. ${ }^{6}$ Fibroadenoma was the commonest BBD (32\%) which is comparable with other studies. ${ }^{6,8}$. The study conducted at Nepalgunj Medical College also found fibroadenoma to be the commonest. (32.57\%). ${ }^{6}$ In this study the commonest age of fibroadenoma was in $3^{\text {rd }}$ and $4^{\text {th }}$ decade of life. This agrees with the literature reports. ${ }^{3,9}$

The inflammatory conditions consisting breast abscess were the second most common BBD, which accounted for $26 \%$ of all the cases. This is similar to the findings from other studies conducted in Nepal by R Kumar $(22 \%)^{7}$ and Khan S el at (24\%). ${ }^{6}$

Breast abscess are often related to lactation. ${ }^{9,20}$ This may be because of lack of hygiene and improper breast feeding. ${ }^{20}$ In the present study all the women with breast abscess were lactating mother and were between 20-30 yrs .Only one case was identified in a non lactating mother. J.Dodd also reported in his study that breast abscess might occur in non lactating mother. ${ }^{20}$

Mastalgia (22\%) seemed to be less common in our setup in contrast to the studies in neighboring countries by Sukla ${ }^{11}$ and Khanna ${ }^{12}$ who reported it to account for $70 \%$ of BBD. They found cyclic mastalgia to be more common than non cyclic mastalgia with majority being in the $2^{\text {nd }}$ and $3^{\text {rd }}$ decade of life respectively. This is comparable to our study which also found cyclic mastalgia to be more common $(n=16)$ then noncyclical mastalgia $(n=6)$. The mean age of patient with cyclic mastalgia fall on $3^{\text {rd }}$ decade and for non cyclic mastalgia was in the $4^{\text {th }}$ decade.Thus patient with cyclic mastalgia were younger than those with non cyclic mastalgia $(p=0.02)$. This low incidence of mastalgia explains ignorance of clinical significant of breast symptoms. Most women thinks that if there is lump then only they are aware that it might be cancer as shown by high incidence of women presenting with breast lump in this study.

In Nepal breast cancer is the second common cancer among women after cervical cancer. ${ }^{15}$ The reported incidence and mortality are high in western countries and relatively low in Asian developing countries. ${ }^{1}$ Female in Nepal tend to detect and report breast lumps at a late stage due to ignorance and lace of knowledge of self breast examination. ${ }^{14,19}$ These are reflected in this study by the average duration of symptoms before first presentation of patient with a lump or mastalgia to doctors (11.30 month with SD +/-26.09).

In addition, social taboos connected with the examination of women by male doctors play an important role in prohibiting women with a breast lump or other abnormality to seek medical advice in time, ${ }^{14,19}$ especially in rural Nepal as seen in our studied by low number of breast cancer detection in which ration between benign and malignant was 24:1 and all presented in advance stage.

There are several established risk factors for breast cancer including age at menarche, late menopause, parity, breast feeding, family history, previous breast biopsy, radiation. ${ }^{16-18}$ In the present study the women with breast cancer had no risk factors mentioned above except for advance age which itself is one of the risk factors for developing breast cancer.

In our study only twenty one women of all surveyed were aware of breast self examination (BSE) with the rest stating that they had no idea. The studies suggesting the effectiveness of BSE has been published in 1978. ${ }^{21-22}$ The studies has found that women who reported that they had been BSE performers had their breast cancer detected at a smaller size and at earlier clinico-pathological stage. ${ }^{22}$ American Cancer Society also urges women to perform BSE once a month. ${ }^{23} \mathrm{BSE}$ will be important in a developing country like ours where mammography is not always available.

\section{Limitation}

This study was a hospital-based and used convenient sampling method due to time restriction. This may 
not reflect the general population but is helpful to describe the case mixed in general outpatient.

\section{Conclusion}

We conclude from this study that BBD were the most common breast lesion. Breast carcinoma was less frequent but reached to hospital in very late stage. Majority of patients with breast abscess were lactating mothers. A large number of the women surveyed did not know or simply did not perform breast self examination. All of these have important public health implications. General practitioner being the first contact doctor should be competent in assessing and managing majority of breast problems so that only necessary and timely referrals are made. General practitioners can also use the opportunity to properly educate and teach breast care and method of BSE.

\section{References}

1. Bradber Johan and Thompson Keith. Lumps in the breast. Surgical problems in clinical practice by Johan Fry and Hadley Arnold publication Ltd. 1987:56-67.

2. Broad of the Faculty of Clinical Radiology. The Royal College of Radiologist. Guidance on screening and symptomatic breast imaging. Royal College of Radiologist, London [online].2003 June [cited 2006 Feb 3]; [29 screen].Available from: URL:http:// www.rcr.ac.uk/index.asp? Page ID = 310\&Publication ID=84.

3. Brennan M, Houssami N, and French J. Management of benign breast condition. Australian family Physician 2005 April; 34(4):253-255.

4. Morrow M. The Evaluation of Common Breast Problems. American Family Physician [serial online] 2000 April 15 [cited 2006 Jan 8]; 61(8): [11 screen]. Available from: URL: http:// www.aafp.org/afp/20000415/2371.html.

5. Lewis O.ICPC-2 categorization of general outpatient presentation. BPKIHS 2006 March unpublished.

6. Khan S, Kapoor AK, Khan IU, Shrestha GB, Singh P. Prospective study of pattern of breast disease at Nepalgunj Medical College, Nepal. KUMJ 2003; 1(2): 95-100.
7. R Kumar. A Clinicopathologic Study of Breast Lumps in Bhairahwa, Nepal. Asian Pacific Journal of Cancer Prevention, Vol 11, 2010.

8. Malik MAN, Salahuddin O, Azhar M, Dilawar O, Irshad H, Sadia, Salahuddin A. Breast diseases; Spectrum in Wah Cantt; POF Hospital Experience. Professional Med J Sep 2010; 17(3):366-372.

9. Murtagh J.General Practice. $3^{\text {rd }}$ ed.Sydney: McGraw Hill Australia, 2003.p.966-971.

10. U Krisnaswamy U. Profile of benign breast diseases in Urban India. Indian Journal of Surgery 2003 March-April; 65(2):178-181.

11. Sukl HS, Kumar S.Benign Breast Disorder in non western population: part 2-Benign Breast disorders in India. World J Surg 1989; 13:746-9.

12. Khann AK, Tapodar J, Misra MK.Spectrum of benign breast disorders in a university hospital.J India Med Assoc.1997;95:5-8.

13. Shrestha HG, Dali S, Sayami G, Osti B, Amatya VJ and Basnet RB. Present cancer scenario and its changing pattern at T.U. Teaching Hospital, Nepal. J Nep Med Assoc 1997; 35: 45-51.

14. Sayami P, Singh BM, Singh Y, Timila R, Shrestha $\mathrm{U}$, Sayami G et al. Retrospective analysis of breast cancer cases and surgical treatment in period of ten years. J Nep Med Assoc 2001; 40: 112-119.

15. BB Vaidya, AG Fletcher. Incidence of malignant tumor in Nepal-A 12 year study. J Nep Assoc Souvenir 1983; 21(1): 67-83.

16. California Department of Health Services. Cancer Detection Section. Breast Expert Workgroup. Breast cancer diagnostic algorithm fir primary care provider. [Online] $3^{\text {rd }}$ ed.2005 June [cited 2006 Jan 15]; Available from: URL www.qap.sdev.edu.

17. Iglehart JD, Kaelin CM. Disease of the breast.In: Townsend CM, Neauchamp RD, Evers BM, and Mattox KL. Sabiston textbook of seugery. $17^{\text {th }}$ ed. Philadelphia: Saunders; 2004.p.881-885.

18. Jones RC, Epidemiology-risk factors. In: Hindle WH. Breast Disease for gynecology. Norwalk: Appleton \& Lange; 1990. p.29-36

19. Y Singh, P Maskey (2002). The price of neglect in breast cancer. Network- The Newsletter of the International Network for Cancer Treatment and Research, [online], 3(1).Available from 
URL:http:/www.inctr.org/publications/ 2002_v03_n01_s04.shtml [Accessed August 2006.]

20. Baily's and Love's Short practice of surgery. Edited by RCG Russell, Norman S Williams, Christopher JK Bull strode 23rd edition. Published by Chapman and HALL medical, Madras, India.

21. Foster RS Jr Lang SP, Costanza MC, et al. Breath self examination practices and breastcancer stage. N Engl J Med 1978; 299:265-270.
22. Greenwald P, Nasca PC, Lawrence CE, et al. Estimated effect of breast self-examination and routine physician examination on breast-cancer mortality. N Engl J Med 1978; 299:271-273.

23. Smith et al. American Cancer Society Guidelines for Breast Cancer Screening.CA A Cancer Journal for Clinician 2003; 53(3):141. 